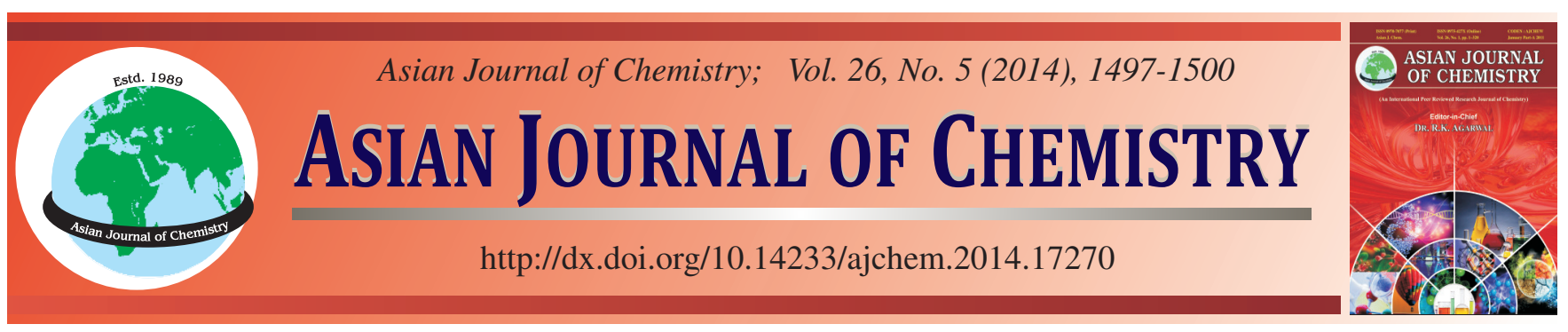

\title{
Photocatalytic Degradation using MWCNTs Modified with Fe(III)-Doped ZnO for Water Treatment $\dagger$
}

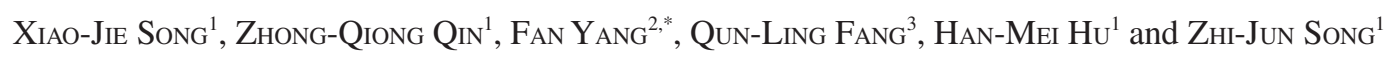

${ }^{1}$ School of Materials and Chemical Engineering, Anhui Jianzhu University, Hefei 230026, P.R. China

${ }^{2}$ Department of Chemistry, Anhui Medical University, Hefei 230026, P.R. China

${ }^{3}$ School of Medical Engineering, Hefei University of Technology, Hefei 230009, P.R. China

*Corresponding author: Tel: +86 551 65161138; E-mail: fyang99@mail.ustc.edu.cn

Published online: 1 March 2014;

AJC-14811

$\mathrm{Fe}(\mathrm{III})$ doped $\mathrm{ZnO}$ nanoparticles were introduced onto the surface of multi-walled carbon nanotubes (MWCNTs) via in situ chemical precipitation method. The products MWCNTs modified with $\mathrm{Fe}(\mathrm{III})$-doped $\mathrm{ZnO}$ nanocomposites (MWCNTs/Fe(III)/ZnO) were characterized by X-ray diffraction, transmission electron microscopy and energy dispersive X-ray spectroscopy. The effects of the ratio of reactants on its dispersion in aqueous solution were analyzed. The nanocomposites with $0.5 \mathrm{~mol} \% \mathrm{Fe}$ (III) showed satisfactory photocatalytic activity in the removal of methyl orange from aqueous solution. Moreover, existence of MWCNTs and doped Fe(III) enhanced the photocatalytic activity of $\mathrm{ZnO}$.

Keywords: Carbon nanotubes, $\mathrm{ZnO}, \mathrm{Fe}(\mathrm{III})$ doped, Photocatalytic activity, Methyl orange.

\section{INTRODUCTION}

As an important wide-bandgap semiconductor $(3.37 \mathrm{eV})$ with a large exciton binding energy $(60 \mathrm{meV}), \mathrm{ZnO}$ has received widespread attention because of its excellent performance in electronics, optics and photonics systems ${ }^{1}$. A range of $1 \mathrm{D} \mathrm{ZnO}$ nanostructures have been fabricated ${ }^{2}, \mathrm{ZnO}$ nanoparticles and quantum dots have been synthesized by different methods ${ }^{3,4}$ and can also be assembled into 1D structures ${ }^{5}$. Due to their tubular morphology and unique electronic properties, multiwalled carbon nanotubes (MWCNTs) are the best candidates for the preparation of photocatalytic composites. Kim ${ }^{6}$, Park and co-workers ${ }^{7}$ have reported the coating of $\mathrm{ZnO}$ nanorods on carbon nanotubes (CNTs) by chemical vapor deposition (CVD) in a tube furnace. Gao and co-workers ${ }^{8,9}$ have reported the deposition of $\mathrm{ZnO}$ particles on MWCNTs and their enhanced photocatalytic activity.

However, some modifications are needed for the sake in photocatalytic degradation of organic dyes. Thus, particular efforts have been dedicated to modify MWCNTs/ZnO with $\mathrm{Fe}(\mathrm{III})$ ions. MWCNTs/Fe(III)/ZnO is observed as a catalyst with high efficiency because of its large surface area, pore volume and porous channel ${ }^{10}$ as well as effectiveness in enhancing the rate of the reaction. The amount of Fe(III) used is one of critical parameters in catalyst preparation as excessive amount could negatively affect the rate of reaction.

Wang et al. ${ }^{11}$ did a preliminary study on the roles of $\mathrm{Fe}(\mathrm{III}) /$ $\mathrm{TiO}_{2}$ in combination with the ultrasound for the degradation of azo fuchsine. They reported that synergistic effect of Fe(III) ions as dopants was achieved when used in combination with ultrasonic irradiation.

Taking the above consideration into account, a new nanocomposites material consisting of $\mathrm{Fe}$ (III) doped $\mathrm{ZnO}$ nanoparticles (NPs) and MWCNTs was prepared by a facile and versatile approach. In this work, $\mathrm{Fe}$ (III) doped $\mathrm{ZnO}$ nanoparticles were introduced onto the surface of MWCNTs by in situ chemical precipitation method. The specific aim was to investigate the effect of MWCNTs/Fe(III)/ZnO on photocatalytic behaviours.

\section{EXPERIMENTAL}

Multi-walled carbon nanotubes (MWCNTs, > $90 \%$ purity) were purchased from Shengzhen Nanotech Port Co., Ltd. The average outer diameter of MWCNTs was between 20 and 40 $\mathrm{nm}$ the length was up to a dozen micrometer. The MWCNTs were prepared by the catalytic decomposition of $\mathrm{CH}_{4}$ before

†Presented at The 7th International Conference on Multi-functional Materials and Applications, held on 22-24 November 2013, Anhui University of Science \& Technology, Huainan, Anhui Province, P.R. China 
use. Ferric chloride hexahydrate $\left(\mathrm{FeCl}_{3} \cdot 6 \mathrm{H}_{2} \mathrm{O}, \mathrm{AR}\right)$, sodium dodecyl sulfacte ( $\mathrm{SDS}, \mathrm{AR})$, ammonium bicarbonate $\left(\mathrm{NH}_{4} \mathrm{HCO}_{3}\right.$, $\mathrm{AR})$, zinc nitrate $\left(\mathrm{Zn}\left(\mathrm{NO}_{3}\right)_{2}, \mathrm{AR}\right)$ and methyl orange (AR) were all purchased from Sinopharm Chemical Reagent Co., Ltd. These reagents were used directly without any further purification.

Synthesis of MWCNTs/Fe(III)/ZnO: $2.02 \mathrm{~g}$ MWCNTs were added into $150 \mathrm{~mL}$ nitric acid solution. The mixture was refluxed with stirring for $4 \mathrm{~h}$ at $80^{\circ} \mathrm{C}$. The acid-treated MWCNTs were collected by filtration, washed with deionized water for several times until neutral and dried at $70{ }^{\circ} \mathrm{C}$ overnight. The purified MWCNTs were dispersed in $80 \mathrm{~mL}$ SDS (1 wt \%) aqueous solution by ultrasonication for $2 \mathrm{~h}$ to modify the MWCNTs surface.

$50 \mathrm{~mL} \mathrm{NH}_{4} \mathrm{HCO}_{3}(0.4 \mathrm{~mol} / \mathrm{L})$ solution, MWCNTs adsorbed SDS and $\mathrm{FeCl}_{3} \cdot 6 \mathrm{H}_{2} \mathrm{O}$ were mixed into a flask, then $50 \mathrm{~mL}$ $\mathrm{Zn}\left(\mathrm{NO}_{3}\right)_{3}(0.4 \mathrm{~mol} / \mathrm{L})$ solution was added into the reaction mixture slowly. The mixture was stirred at $80{ }^{\circ} \mathrm{C}$ for $0.5 \mathrm{~h}$, cooled to room temperature and sonicated for $10 \mathrm{~min}$. The product was filtrated and washed with deionized water repeatedly, then dried in oven at $120^{\circ} \mathrm{C}$ for $1 \mathrm{~h}$ and calcined at $500{ }^{\circ} \mathrm{C}$ for $2 \mathrm{~h}$.

Synthesis of $\mathrm{ZnO}$ nanoparticles: Was put into a flask with mixing temperature of $80{ }^{\circ} \mathrm{C}, 50 \mathrm{~mL} \mathrm{Zn}\left(\mathrm{NO}_{3}\right)_{3}(0.4$ $\mathrm{mol} / \mathrm{L})$ solution was added into $50 \mathrm{~mL} \mathrm{NH}_{4} \mathrm{HCO}_{3}(0.4 \mathrm{~mol} / \mathrm{L})$ solution slowly. The mixed solution was stirred at $80{ }^{\circ} \mathrm{C}$ for $0.5 \mathrm{~h}$ and cooled to room temperature. The product was filtrated and washed with deionized water repeatedly, then dried in oven at $120^{\circ} \mathrm{C}$ for $1 \mathrm{~h}$ and calcined at $500{ }^{\circ} \mathrm{C}$ for $2 \mathrm{~h}$.

Synthesis of Fe(III) doped ZnO nanoparticles: $50 \mathrm{~mL}$ $\mathrm{NH}_{4} \mathrm{HCO}_{3}(0.4 \mathrm{~mol} / \mathrm{L})$ solution and $\mathrm{FeCl}_{3} \cdot 6 \mathrm{H}_{2} \mathrm{O}$ were mixed into a flask and $50 \mathrm{~mL} \mathrm{Zn}\left(\mathrm{NO}_{3}\right)_{3}(0.4 \mathrm{~mol} / \mathrm{L})$ solution was slowly added into the reaction mixture. The mixed solution was stirred at $80^{\circ} \mathrm{C}$ for $0.5 \mathrm{~h}$, cooled to room temperature and sonicated for $10 \mathrm{~min}$. The product was filtrated and washed with deionized water repeatedly, then dried in oven at $120{ }^{\circ} \mathrm{C}$ for $1 \mathrm{~h}$ and calcined at $500{ }^{\circ} \mathrm{C}$ for $2 \mathrm{~h}$.

Photocatalytic properties research of MWCNTs/Fe(III)/ ZnO: The photocatalytic experiment was carried out at $25^{\circ} \mathrm{C}$ pure $\mathrm{ZnO}$ NPsMWCNTs/ZnO composites and MWCNTs/ $\mathrm{Fe}(\mathrm{III}) / \mathrm{ZnO}$ were used as photocatalysts, respectively. $75 \mathrm{mg}$ photocatalyst and $50 \mathrm{~mL}$ methyl orange solution (initial concentration $\mathrm{c}_{0}=50 \mathrm{mg} / \mathrm{L}$ ) were added into a beaker. The mixture was stirred in the dark for $3 \mathrm{~h}$ to reach adsorption equilibrium $^{12}$. The photocatalytic experiments were carried out under UV light ( $365 \mathrm{~nm}, 80 \mathrm{~W}$ ) with stirring. $1 \mathrm{~mL}$ solution at regular intervals was taken out, diluted to $10 \mathrm{~mL}$ and centrifuged at $16000 \mathrm{rpm} / \mathrm{min}$ for $5 \mathrm{~min}$. The supernatant liquid was analysed by UV-visible spectroscopy for the methyl orange concentrationThe characteristic absorption wavelength of methyl orange was $472 \mathrm{~nm}$ which was chosen as the monitored parameter in the process of photocatalytic degradation.

\section{RESULTS AND DISCUSSION}

XRD and EDS: X-Ray powder diffraction (XRD) was carried out on a XRD-6000 X-ray diffractometer (Shimadzu, Japan) with $\mathrm{CuK}_{\alpha}$ radiation $(\lambda=0.15406 \mathrm{~nm}, \mathrm{U}=40 \mathrm{kV}, \mathrm{I}=$ $30 \mathrm{~mA}$ ) at a scanning rate of $0.02^{\circ} \mathrm{s}^{-1}$ in the $2 \theta$ range from 10 - $80^{\circ}$. Fig. 1(a) showed an X-ray diffraction spectrum of the $\mathrm{Fe}$ (III) doped MWCNTs/ZnO nanocompositesThe peak at $2 \theta$ $=26.05^{\circ}$ was the characteristic peak of MWCNTs. Strong diffraction peaks appearing at $31.75,34.41,36.25,47.54$ and $56.62^{\circ}$ were indexed to be the (100), (002), (101), (102) and (110) planes of $\mathrm{ZnO}$ with hexagonal wurtzite structure (JCPDS89-0510), respectively.

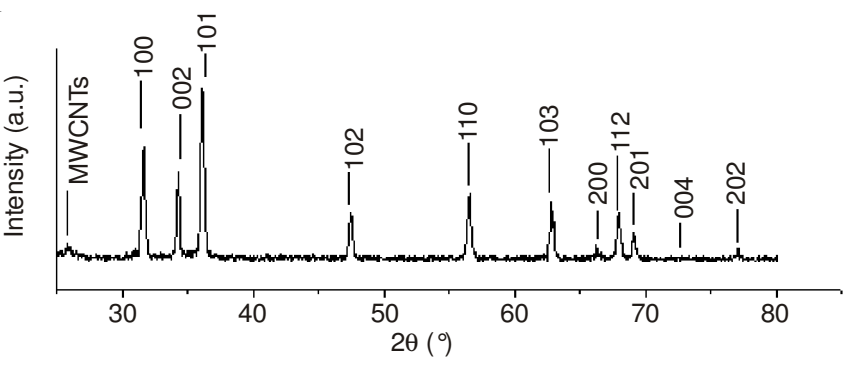

(a)

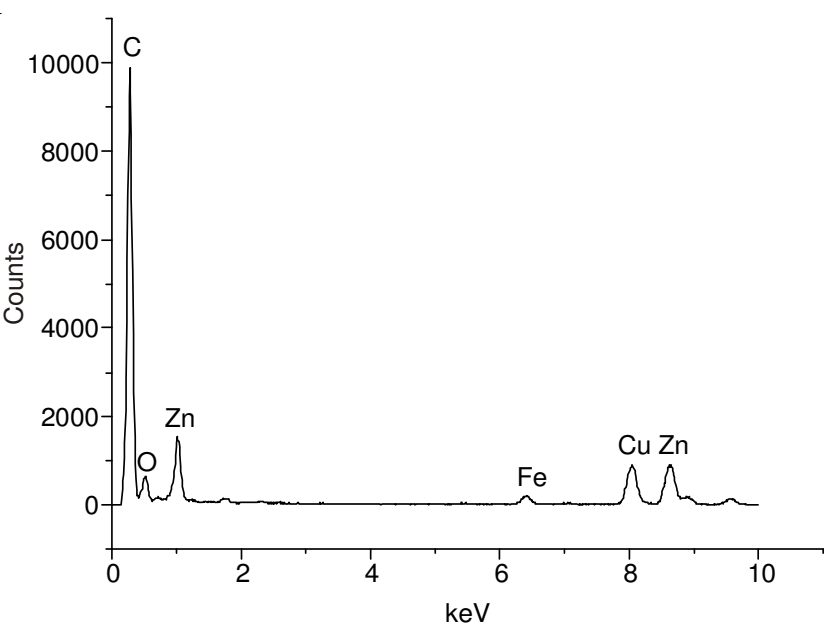

(b)

Fig. 1. XRD (a) and EDS (b) patterns of MWCNTs/Fe(III)/ZnO

EDS of the MWCNTs/Fe(III)/ZnO (Fig. 1b) showed the presence of $\mathrm{Fe}, \mathrm{Zn}, \mathrm{O}$ and $\mathrm{C}$ elements in products, which demonstrated $\mathrm{Fe}(\mathrm{III})$ doped $\mathrm{ZnO}$ nanoparticles were introduced on the surface of MWCNTs.

TEM: The surface mophology of samples was observed on an H-800 transmission electron microscope (TEM, Hitachi).

The TEM images of MWCNTs/Fe(III)/ZnO were shown in Fig. 2. The surface of MWCNTs was covered with a layer of nanoparticles. The size of nanoparticles was almost uniform and the average value estimated from Fig. 2 was 30-40 nm.

Photocatalytic activity: The photocatalytic results of pure $\mathrm{ZnO}$ nanoparticles, MWCNTs/ZnO nanocomposites and MWCNTs/Fe(III)/ZnO were showed in Fig. 3. As shown in Fig. 3, the photocatalytic activity of pure $\mathrm{ZnO}$ nanoparticles (curve a) was much lower than MWCNTs/ZnO nanocomposites (curve b), which showed that MWCNTs greatly enhance the photocatalytic activity of $\mathrm{ZnO}$. At the same time, the photocatalytic activity of MWCNTs/Fe(III)/ZnO was superior to MWCNTs/ZnO nanocomposites.

The possible mechanism could be described as followed: under UV light irradiation, the valence band electrons of $\mathrm{ZnO}$ were excited and moved toward conduction bands, giving rise to the formation of electron and hole pairs. Due to the strong 


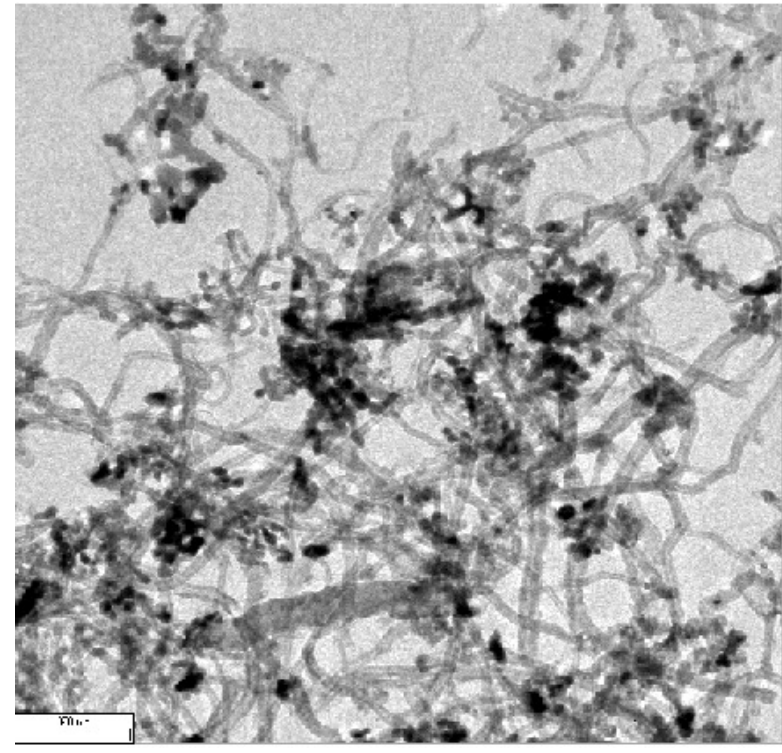

(a)

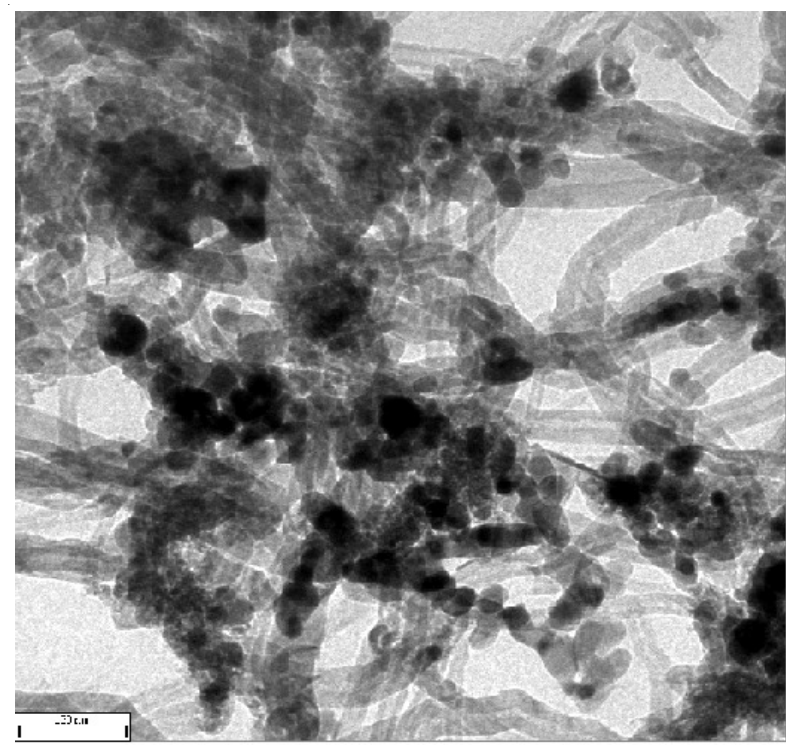

(b)

Fig. 2. TEM images of MWCNTs/Fe(III)/ZnO

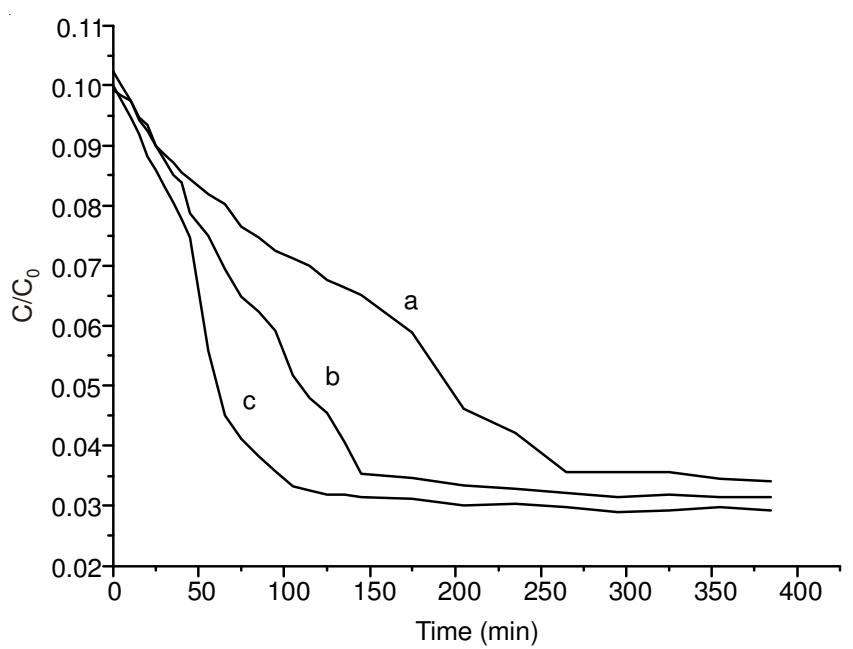

Fig. 3. Degradation results of methyl orange solution by pure $\mathrm{ZnO}$ nanoparticles (a), MWCNTs/ZnO nanocomposites (b) and MWCNTs/Fe(III)/ZnO (c) under exposure to UV light interfacial connection between $\mathrm{ZnO}$ nanoparticles and MWCNTs, the excited $\mathrm{e}^{-}$of the conduction band of $\mathrm{ZnO}$ nanoparticles could migrate to MWCNTs, which were relatively good electron acceptors ${ }^{13,14}$. So the recombination of the $\mathrm{e}^{-} / \mathrm{h}^{+}$pairs was retarded, which resulted in the promotion of photocatalytic activity in $\mathrm{ZnO}$ nanoparticles. Another possible reason was the improvement of the dispersion of $\mathrm{ZnO}$ nanoparticles (from Fig. 2b) and thus the enhancement of the photo absorption efficiency of $\mathrm{ZnO}$ nanoparticles.

Fig. 4 showed the photocatalytic activity of MWCNTs/ $\mathrm{Fe}(\mathrm{III}) / \mathrm{ZnO}$ with different dosage of $\mathrm{Fe}(\mathrm{III})$ ranging from 0.5 to $3.5 \%$, it was clear that as the dosage of Fe(III) reduced, the peaks decreased.

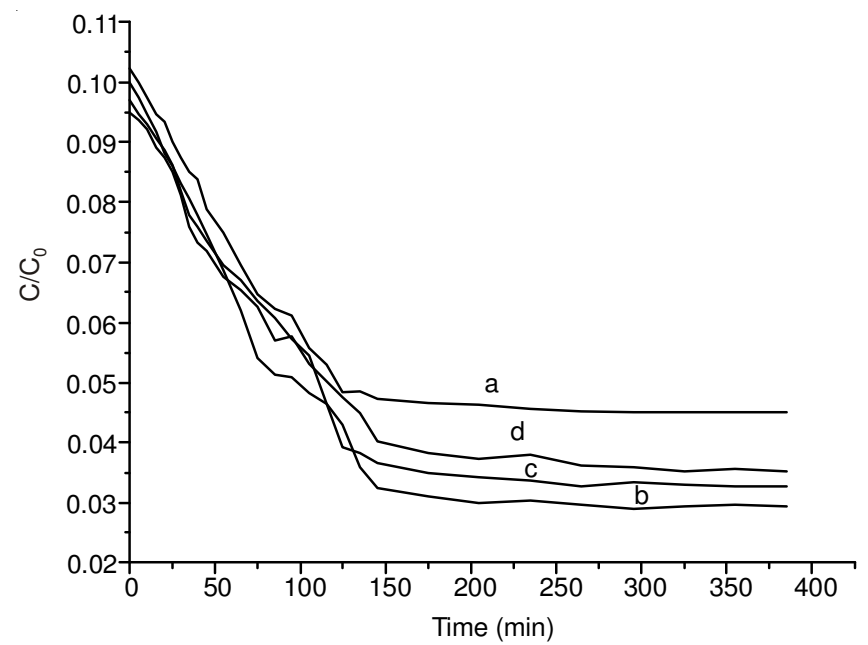

Fig. 4. Degradation results of methyl orange solution by MWCNTs/ZnO nanocomposites (a), MWCNTs/Fe(III)/ZnO(with $0.5 \% \mathrm{Fe}(\mathrm{III})$ ) (b), MWCNTs/Fe(III)/ZnO (with $1.5 \% \mathrm{Fe}(\mathrm{III})$ ) (c) and MWCNTs/ $\mathrm{Fe}(\mathrm{III}) / \mathrm{ZnO}$ (with $3.5 \% \mathrm{Fe}(\mathrm{III})$ ) (d) under exposure to UV light

The removal ratio of dye by MWCNTs/ZnO nanocomposites was $42 \%$ (curve a) and the ratio of dye removed by MWCNTs/Fe(III)/ZnO could increase obviously (curve d, c and b). Effect of $\mathrm{Fe}(\mathrm{III})$ loading in $\mathrm{ZnO}$ on methyl orange removal was also investigated by varying the $\mathrm{Fe}$ (III) contents from $0.5-3.5 \%$. The removal ratio of methyl orange increased to $68 \%$ within 150 min by using $0.5 \% \mathrm{Fe}$ (III) doped MWCNTs/ $\mathrm{ZnO}$, which indicated the positive role of $\mathrm{Fe}(\mathrm{III})$ ions. The dye removal was ascribed to the combination of ultrasonic irradiation and $\mathrm{ZnO}$ particles that led to the enhancement in the production of $\cdot \mathrm{OH}$ radicals, the Equations were shown as below. In this case, the improvement in the removal of dye could be attributed to the presence of Fe(III) ions doped in $\mathrm{ZnO}$. The presence of the Fe(III) ions would also introduce more oxygen vacancies in the crystal lattice or on the surface of $\mathrm{ZnO}$. These oxygen vacancies favoured the adsorption of water and the formation of surface hydroxyl group to consequently promote catalytic activity ${ }^{15}$.

$$
\begin{aligned}
& \mathrm{ZnO} \stackrel{\mathrm{h} v}{\longrightarrow} \mathrm{e}^{-}+\mathrm{h}^{+} \\
& \mathrm{e}^{-}+\mathrm{O}_{2} \rightarrow \cdot \mathrm{O}_{2}^{-} \\
& \cdot \mathrm{O}_{2}^{-}+\mathrm{H}_{2} \mathrm{O} \rightarrow \mathrm{HOO}+\mathrm{OH}^{-} \\
& 2 \mathrm{HOO} \cdot \rightarrow \mathrm{H}_{2} \mathrm{O}_{2}+\mathrm{O}_{2} \\
& \mathrm{Fe}^{3+}+\mathrm{H}_{2} \mathrm{O}_{2} \rightarrow \mathrm{Fe}(\mathrm{OOH})^{2+}+\mathrm{H}^{+} \\
& \mathrm{Fe}(\mathrm{OOH})^{2+}+\rightarrow \mathrm{Fe}^{2+}+\mathrm{HO}_{2} \\
& \mathrm{Fe}^{2+}+\mathrm{H}_{2} \mathrm{O}_{2} \rightarrow \mathrm{Fe}^{3+}+\cdot \mathrm{OH}+\mathrm{OH}^{-}
\end{aligned}
$$




\section{Conclusion}

MWCNTs/Fe(III)/ZnO were fabricated using in situ chemical precipitation method. Close contact between $\mathrm{ZnO}$ and carbon nanotubes could improve the interfacial electron transfer and restrain the $\mathrm{e}^{-} / \mathrm{h}^{+}$pair recombination of $\mathrm{ZnO}$, by which photocatalytic activity was enhanced. MWCNTs could promote effectively the photocatalytic activity of $\mathrm{ZnO}$ nanoparticles in the elimination of organic dye. MWCNTs/Fe(III)/ZnO enhanced photocatalytic activity and MWCNTs/Fe(III)/ $\mathrm{ZnO}$ (with $0.5 \mathrm{~mol} \% \mathrm{Fe}(\mathrm{III})$ ) gave superior photocatalytic activity in the removal of methyl orange from aqueous solution.

\section{ACKNOWLEDGEMENTS}

This work was supported by National Natural Science Foundation for Young Scholars (No. 21205026) and Anhui Province Natural Science Foundation (No. KJ2013B061).

\section{REFERENCES}

1. Z.L. Wang, J. Phys. Condens. Matter, 16, R829 (2004).

2. Z.L. Wang, Mater. Today, 7, 26 (2004).

3. Z.Y. Jiang, Z.X. Xie, X.H. Zhang, S.-C. Lin, T. Xu, S.-Y. Xie, R.-B. Huang and L.-S. Zheng, Adv. Mater., 16, 904 (2004).

4. J. Joo, S.G. Kwon, J.H. Yu and T. Hyeon, Adv. Mater., 17, 1873 (2005).

5. C. Pacholski, A. Kornowski and H. Weller, Angew. Chem. Int. Ed., 41, 1188 (2002).

6. H. Kim and W. Sigmund, Appl. Phys. Lett., 81, 2085 (2002).

7. S.Y. Bae, H.W. Seo, H.C. Choi, J. Park and J. Park, J. Phys. Chem. B, 108, 12318 (2004)

8. J. Sun, L. Gao and M. Iwasa, Chem. Commun., 832 (2004).

9. L. Jiang and L. Gao, Mater. Chem. Phys., 91, 313 (2005).

10. J. Zhu, W. Zheng, B. He, J. Zhang and M. Anpo, J. Mol. Catal. Chem., 216, 35 (2004).

11. J. Wang, W. Sun, Z. Zhang, Z. Jiang, X. Wang, R. Xu, R. Li and X. Zhang, J. Colloid Interf. Sci., 320, 202 (2008).

12. F.J. Zhang, W.C. Oh and K. Zhang, Mater. Res. Bull., 47, 619 (2012).

13. Y. Sun, S.R. Wilson and D.I. Schuster, J. Am. Chem. Soc., 123, 5348 (2001).

14. P. Serp, M. Corrias and P. Kalck, Appl. Catal. A, 253, 337 (2003).

15. A. Mehrdad and R. Hashemzadeh, Ultrason. Sonochem., 17, 168 (2010). 